\title{
Çok Kesitli Bilgisayarlı Tomografi ile Torakal Aortik Varyasyonlarının Değerlendirilmesi
}

\author{
@ (iD) Uzm. Dr. Murat Değer ${ }^{1}$, @ (iD) Dr. Öğr. Üyesi Fatma Öztürk Keleş² \\ ${ }^{1}$ Mardin Kızıltepe Devlet Hastanesi, Radyoloji Bölümü, Mardin, Türkiye \\ ${ }^{2}$ Hatay Mustafa Kemal Üniversitesi Tıp Fakültesi Radyoloji Anabilim Dalı, Hatay, Türkiye
}

Öz

\section{Çok Kesitli Bilgisayarlı Tomografi ile Torakal Aortik Varyasyonlarının Değerlendirilmesi}

Amaç: Bu çalışmada çok kesitli bilgisayarlı tomografi (ÇKBT) ile torakal aortik varyasyonları ve görülme sıklığını değerlendirmeyi amaçladık.

Gereç ve Yöntem: Hastanemiz Radyoloji Ünitesinde Ocak 2016-Mart 2019 tarihleri arasında çekilen 2978 kontrastlı toraks bilgisayarlı tomografi tetkiki torakal aortik varyasyon varlığı, varyasyonların cinsiyet farklılı̆̆ yönünden retrospektif olarak değerlendirildi.

Bulgular: Çalıșmamızda torakal aortik varyasyonu görülme oranı \%22.5 olup bu oran kadınlarda \%25.76, erkeklerde \%20.63 idi. En sık görülen torakal aortik varyasyon trunkus brakiosefalikus ile sol ana karotis arter aortadan ortak kökten orjin almasıdır (Bovine arkı). Görülme oranı \%13.76 idi. Diğer görülen varyasyonlar izole sol vertebral arterin aortadan çıkması, arkus aorta aberran sağ subklavyen $\operatorname{arter}($ ARSA) varyasyonu, sağ arkus aorta ve aort koarktasyonudur. Bu varyasyonlara eșlik eden ikincil varyasyon ise sol vertebral arterin arkus aortadan orjin almasıdır. Kadın-erkek oranı açısından bakıldığında bovine arkı ve sağ arkus aorta varyasyonunda istatiksel olarak anlamlı fark izlenmiş olup diğer varyasyonlarda anlamlı fark izlenmedi.

Sonuç: Torakal aortik varyasyonlar çoğunlukla asemptomatik olup bazı tipleri semptomatiktir. Bu varyasyonların görüntüleme özelliklerine aşina olmak, doğru tanı ve sınıflandırma ve cerrahi tedaviye rehberlik etme açısından önemlidir. Kontrastlı ÇKBT noninvaziv bir görüntüleme yöntemi olup, bu varyasyonların kapsamlı bir değerlendirmesini sağlamaktadır.

Anahtar Kelimeler: Torasik Aort Anomalileri, Komplet Vasküler Halka, Çok Kesitli Bilgisayarlı Tomografi

\section{Abstract}

\section{Evaluation of Thoracic Aortic Variations by Multi-Slice Computed Tomography}

Objective: In this study, we aimed to evaluate the thoracic aorta variations and their incidence with multidedector computed tomography (MDCT).

Materials and Methods: Two thousand nine hundred seventy-eight contrast-enhanced thorax computed tomography examinations taken in the Radiology Unit of our hospital between January 2016 and March 2019 were retrospectively evaluated in terms of the presence of thoracic aortic variation and gender differences of the variations.

Results: In our study, the incidence of thoracic aortic variation was $22.5 \%$, this rate was $25.76 \%$ in women and $20.63 \%$ in men. The most common thoracic aorta variation was originating from the common root of the truncus brachiocephalicus and left common carotid artery aorta (Bovine arc). The incidence rate was 13.76\%. Other observed variations were the origin of the isolated left vertebral artery from the aorta, aberrant right subclavian artery (ARSA) variation in the aortic arch, right aortic arch and aortic coarctation. The secondary variation accompanying these variations was the origin of the left vertebral aorta in the aortic arch. In terms of female-early ratio, a statistically significant difference was observed in the bovine arc and right aortic arch variation, but no significant difference was observed in other variations.

Conclusion: Thoracic aortic variations are mostly asymptomatic and some types are symptomatic. Familiarity with the imaging features of these variations is important for accurate diagnosis and classification, and to guide surgical treatment. Contrast-enhanced MDCT is a non-invasive imaging method, providing a comprehensive evaluation of these variations.

Keywords: Thoracic Aorta Anomalies, Complete Vascular Ring, Multi-slice Computed Tomography 


\section{Giris}

Aortik ark ve dallarının gelișimi fetal hayatın ilk birkaç haftasında bașlayan kompleks bir süreci içerir. Arkus aortanın normal konfigürasyonu sol arkus aorta ve arkus aortadan 3 büyük dalın çıkmasıdır. Bu üç büyük dal trunkus brakiosefalikus (TB), sol ana karotis arter (LCC) ve sol subklavyan arter (LS) dir. TB, sağ subklavyan arter (RS) ve sağ ana karotis arter (RCC) olarak ikiye ayrılır (1). Bu dallanma türü insanlarda \%49.7'den \%94.3'e kadar değișen sıklıkta görülmektedir (2).

Aortik arkın embriyolojik gelișimine bakıldığında; Trunkus arteriozus, primitif kalpten kaynaklanır ve altı çift kemere ayrılır. Bu arterler, farenksin her iki tarafında birleșerek iki taraflı dorsal aortu olușturur. Üçüncü gebelik haftası boyunca, bu dorsal aortalar dördüncü torasik vertebra seviyesinde kaynaşarak kaudal olarak tek bir desendan aorta haline gelirler. Birinci, ikinci ve beşinci kemerler daha sonra geriler. Üçüncü kemerler karotid arterleri oluștururlar. Sağdaki dördüncü kemer, brakiosefalik ve sağ subklavyen arteri, soldaki ise sol subklavyen arteri ve sonradan desendan aortaya katılacak olan aort arkını oluşturur. Altıncı brakiyal ark, ana pulmoner arter, sol ve sağ pulmoner arter ve duktus arteriozusu olușturur (35) (șekil 1).

Torasik aorta varyasyonları genellikle radyolojik çalışmalarda rastlantısal olarak saptanır. Disfaji ve dispne gibi semptomlara yol açabilen aberran sağ subklavyan arter anomalisi dıșındaki diğer anatomik çeșitlilikler genellikle belirgin bir semptoma yol açmazlar $(7,8)$. Bu varyasyonların bilinmesi özellikle baș-boyun ve gögüs bölgesinde yapılması planlanan radyolojik veya cerrahi girișimlerde gelișebilecek komplikasyonların önlenmesi için hayati önem taşımaktadır.

Biz bu çalıșma ile kontrastlı toraks BT tetkiklerini retrospektif olarak değerlendirerek torakal aortik varyasyonların çeșitliliğini ve sıklı̆̆ını, cinsiyetler arasındaki oranını tespit etmeyi amaçladık.

\section{GEREÇ VE YÖNTEM}

Hastanemiz Radyoloji Ünitesinde Ocak 2016-Mart 2019 tarihleri arasında çeșitli nedenlerle kontrastlı Toraks BT tetkiki çekilen 2978 hastanın tetkikleri çalıșmaya dahil edildi. Görüntüler ünitemizde bulunan 64 dedektörlü BT (Toshiba Aquilion 64 MDCT, Toshiba Medical Systems, Otawara, Japan) ile alınmıștı. Rutin çekim prokolünde rotasyon süresi $0.75 \mathrm{sn}$, dozu $120 \mathrm{kV}$ ve $250 \mathrm{mAs}$, kolimasyon 64x0.625, pitch değeri 1.375 ve kesit kalınlığı 5 mm șeklinde otomatik olarak ayarlanmıștı. Non-iyonik kontrast madde açılan damar yolundan otomatik enjektör (Mallinckrodt Optivantage injection system model) ile $80 \mathrm{~mL} 4 \mathrm{~mL} / \mathrm{sn}$ hız ile verilmiști. Elde edilen görüntüler ünitemizdeki görüntüleme monitörlerindeki Osirix MD (Pixmeo Labs, Geneva, Switzerland) programı ile retrospektif olarak değerlendirildi. Çekilen kontrastlı toraks BT tetkikleri torakal aortik varyasyonların çeşitliliği ve sıklığı yönünden

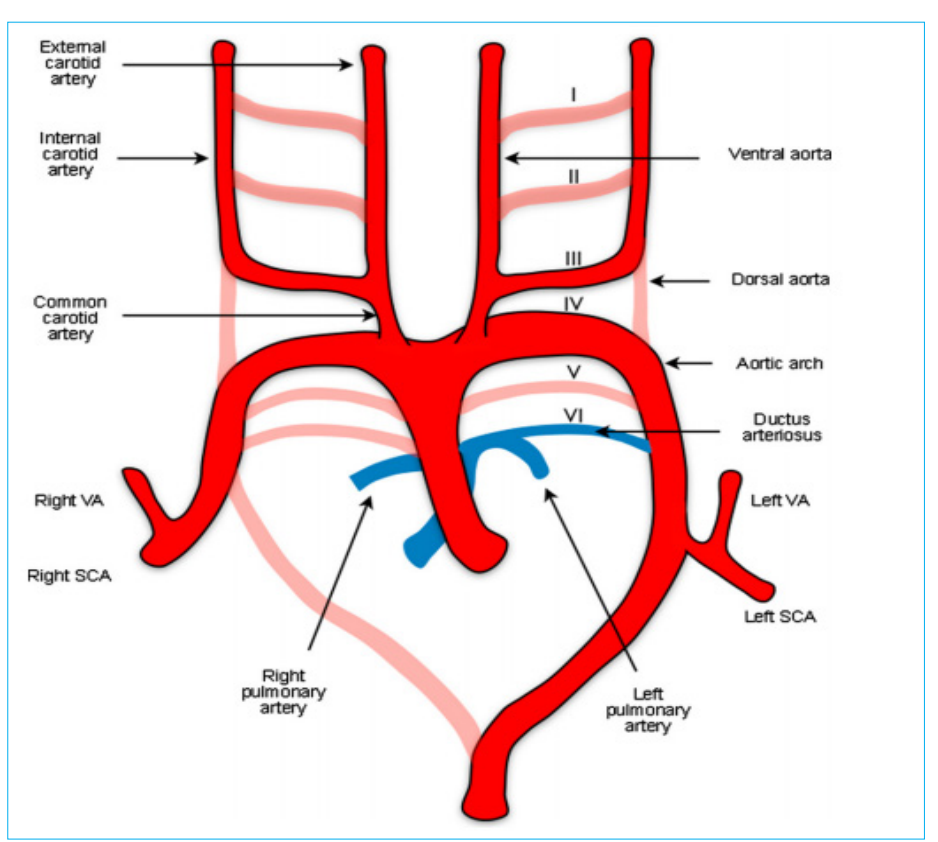

Sekil 1. Aortik ark ve dallarının embriyolojik gelișimini gösteren șematik diyagram (6).

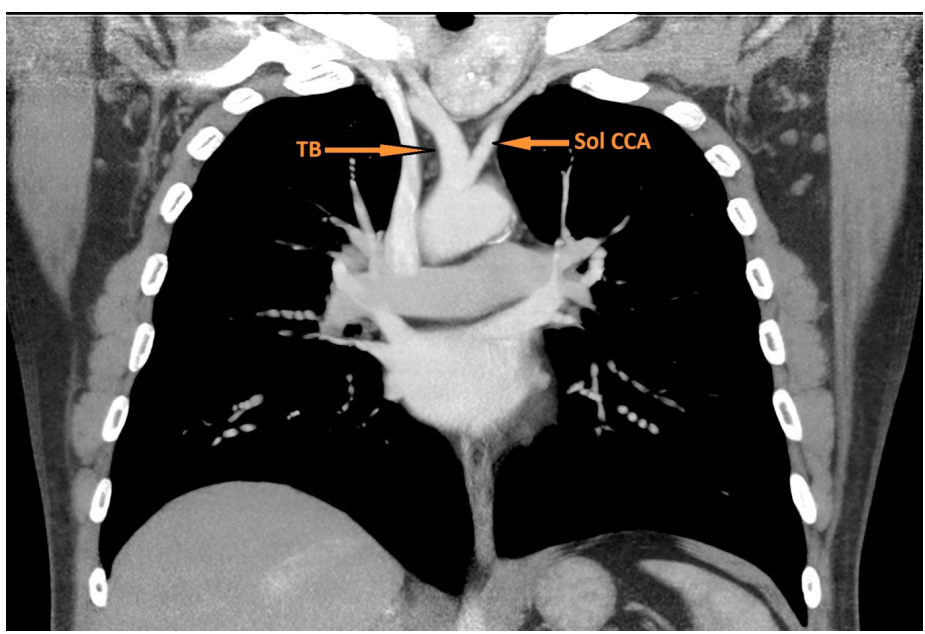

Resim 1. Trunkus brakiosefalikus (TB) ve sol ana karotis arterin (CCA) aynı kökten orjin aldığı bovine arkı varyasyonu.

tek bir radyolog tarafından incelendi. MiP özelliğinden faydalanarak vasküler yapılar her üç planda (aksiyel, koronal ve sagital) incelenmiștir. Bazı hastalarda volüme rendering özelliği kullanılmıştır. Ana vasküler yapılarının anatomisini bozan herhangi bir operasyon geçirmiș olan hastalar çalıșmaya alınmadı. İstatistiksel çalıșmamızda p değeri 0,05'ten küçük değerler anlamlı kabul edildi.

\section{BULGULAR}

Torakal aorta varyasyonları açısından incelenen 2978 hastanın 1895’i (\%63.63) erkek, 1083’ü (\% 36.36) kadındı. Hastaların yașları 18 ile 70 yaș aralığında olup, yaș ortalaması 52.60 \pm 6.24 idi. Kadın hastaların yaș ortalaması $52.52 \pm 4.78$ ve 

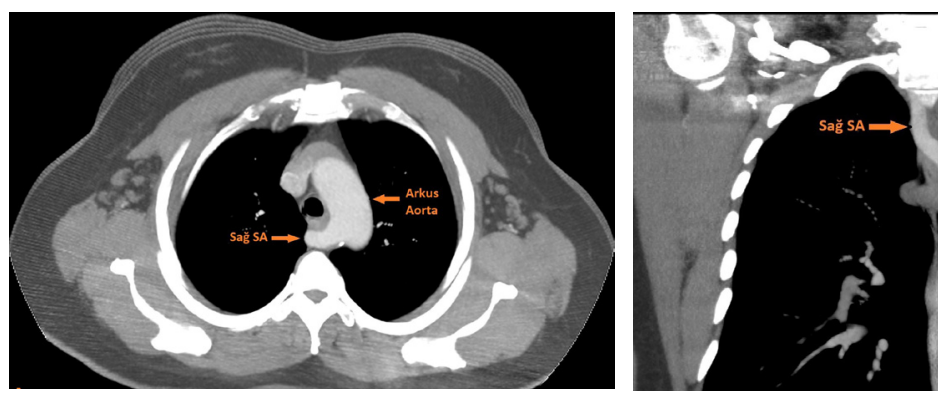

Resim 2 (A,B,C). Sol arkus aortadan son dal olarak ayrilan aberran sağ subklavyen arter (ARSA) varyasyonu. (SA: Subkalvyen arter, CCA: Ana karotis arter)

erkek hastaların yaș ortalaması $52.64 \pm 5.48$ idi. İnceledigimiz toplam 2978 hastanın 670'inde (\%22.5) torasik aortada varyasyon saptanmıștır. Kadın hastaların 279'ında (\%25.76) ve erkek hastaların 391'inde (\%20.63) çeșitli toraks arteryel varyasyonları tespit edilmiștir. Herhangi bir torakal aorta anomalisi olan kadın hastaların 2'sinde ve erkek erken hastaların 1 'inde eșlik eden bir konjenital kalp hastalığı saptandı.

Incelenen hastaların 410'unde (\%13.76) en yaygın torasik aorta varyasyonu olan trunkus brakiosefalikus ile sol ana karotis arterin aortadan ortak kökten orjin aldığı (bovine arkı) görülmüștür (Resim 1). Bu hastaların 220'si erkek hasta, 190'ı kadın hasta idi. 35 hastada ise bovine arkı ve sol vertebral arter aortadan direkt çıkmaktadır.

Incelenen hastaların 114'ünde (\%3.8) izole sol vertebral arter anormal orijini izlenmektedir. Bu hastaların 79'u erkek, 35 'i kadın idi. Sol vertebral arterin aortik arktan kaynaklandığı hasta sayısı toplam 160’tır (\%5.37).

Toplam 37 (\%1.61) hastada sol arkus aortadan son dal olarak ayrılan aberran sağ subklavyen arter (ARSA) varyasyonu izlenmekte olup hastaların 20'si erkek, 17'si kadın hasta idi. 11 hastada ise ARSA varyasyonu ile birlikte aortadan köken alan sol vertebral arter varyasyonu eșlik etmektedir (Resim2).

Toplam 16 (\%0.53) hastada sağ aortik ark varyasyonu (RAA) izlenmektedir. Kadın hastaların 7'sinde ve erkek hastaların 9'unda bu varyasyon izlenmiștir. Aort koarktasyonu toplam 1 (\%0.03) tane olup erkek cinsiyette saptanmıștır. Çalıșmalmızda çift aortik ark ve servikal ark varyasyonu saptanmamıștır.

Trunkus brakiosefalikus ile sol ana karotis arterin aortadan ortak kökten orijin alan varyasyonu $(p=0.001)$ ve RAA varyasyonun kadın ve erkek hastada görülme oranları karșılaștırıldığında istatiksel olarak anlamlı fark bulundu $(p=0.001)$. Aortik arktan direkt çıkan sol vertebral arter orijin varyasyonu ( $p=0.165)$, ARSA varyasyonu $(p=0.225)$ ve ARSA ile aortik arktan direkt köken alan vertebral arterin eşlik ettiği varyasyonun $(p=1)$ kadın ve erkek hasta oranları karşılaștırıldığında istatiksel olarak anlamlı fark bulunmadı. Tablo 1'de görülen torakal aorta varyasyonları ve kadın-erkek oranları gösterilmiștir.
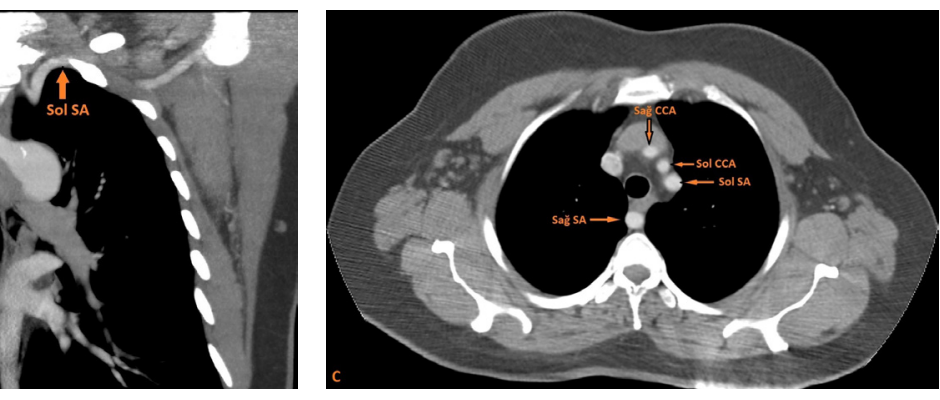

Tablo 1. Torakal Aorta Anomalilerin Kadın ve Erkek Sıklığı

\begin{tabular}{|l|c|c|c|}
\hline & $\begin{array}{c}\text { Erkek } \\
\mathbf{n}(\%)\end{array}$ & $\begin{array}{c}\text { Kadın } \\
\mathbf{n}(\%)\end{array}$ & $\begin{array}{c}\text { Toplam } \\
\mathbf{n}(\%)\end{array}$ \\
\hline $\begin{array}{l}\text { Trunkus brakiosefalikus ile } \\
\text { sol CCA' nın aortik arktan } \\
\text { aynı kökten çıkması }\end{array}$ & $220(11.6)$ & $190(17.54)$ & $410(13.76)$ \\
\hline $\begin{array}{l}\text { Sol vertebral arterin aortik } \\
\text { arktan köken alması }\end{array}$ & $110(5.8)$ & $50(4.61)$ & $160(5.37)$ \\
\hline $\begin{array}{l}\text { Sol vertebral arterin aortik } \\
\text { arktan köken alması ve } \\
\text { trunkus brakiosefalikus ile } \\
\text { sol ccA'nın aortadan tek kök } \\
\text { olarak çıkısı }\end{array}$ & $24(1.26)$ & $11(1.01)$ & $35(1.17)$ \\
\hline $\begin{array}{l}\text { Sol arkus aorta ve aberran } \\
\text { sağ subklavyen arter }\end{array}$ & $20(1.05)$ & $17(1.56)$ & $37(1.24)$ \\
\hline $\begin{array}{l}\text { Sol Arkus Aorta aberan } \\
\text { sağ subklavyen arter ve sol } \\
\text { vertebral arterin aortik } \\
\text { arktan köken alması }\end{array}$ & $7(0.36)$ & $4(0.36)$ & $11(0.36)$ \\
\hline \begin{tabular}{l} 
Sağ arkus aorta \\
\hline Aort Koarktasyonu
\end{tabular} & $9(0.47)$ & $7(0.64)$ & $16(0.53)$ \\
\hline $\begin{array}{l}\text { Anomali saptanan toplam } \\
\text { hasta }\end{array}$ & $391(20.63)$ & $279(25.76)$ & $670(22.50)$ \\
\hline
\end{tabular}

\section{TARTIŞMA}

Torasik aorta varyasyonları yapılan çalışmalarda nadir olmadığı görülmüștür. Çalıșmamızda torasik aorta varyasyon görülme oranı \%22.5 olarak bulduk. Williams ve Edmonds 407 kadavrayı inceledikleri çalıșmalarında arkus aortada varyasyon görülme oranını beyazlarda \%17.8, siyahlarda ise \%37.8 olarak bildirmișlerdir (9). Çalıșmalar arasında görülme oranlarında bu kadar değișiklik olmasının nedeni ırklar arasında görülen farklılıklar olarak düşünülebilir.

Çalıșmamızda arkus aortada varyasyon görülme oranı erkeklerde \%20.63, kadınlarda ise \%25.76 olarak görülmüștür. Karacan ve ark.nın (10) arkus aorta dalları ile ilgili varyasyonları araștırmak amacıyla BT ile yaptığı çalışmada arkus aor- 
tada varyasyon görülme oranları erkeklerde \%20, kadınlarda \%22.1 oranında tespit ederken Ergun ve ark.nın (11) yaptı̆̆ anjiografik çalıșmada bu oran erkeklerde \%26.4, kadınlarda $\% 27$ olarak bulmuşlardır.

Torakal aorta varyasyonları arasında en sık görülen tipi bovine arkı olarak tanımlanan TB ile LCC arterin ortak köken alması olup bizim çalıșmamızda literatürle benzerlik göstermektedir.

Çalıșmamızda bovine arkı görülme oranı \%13.76 olarak tespit ettik. Literatürde bu varyasyon için görülme oranı \%11 ile \%27 arasındadır (7). Çalıșmamızda kadınlarda görülme oranı \%17.54, erkeklerde görülme oranı \% 11.6 olup cinsiyetler arasında istatiksel olarak anlamlı fark bulundu. Ergun ve ark.nın (11) yaptı̆̆ı çalıșmada bu tip varyasyonda cinsiyetler arasında anlamlı fark izlenmemiștir.

ikinci olarak en sık görülen varyasyon sol vertebral arterin arkus aortadan köken aldığı arkus aortadan 4 dalın çıktığı tiptir. Literatürde görülme bu tipin görülme oranı $\% 0.79$ ile $\% 8$ arasında değișmektedir (12). Çalıșmamızda izole sol vertebral arterin arkus aoratadan köken aldığı varyasyon tipi \%3.8 oranında görülmüştür. Bu tip varyasyonun kadınlarda görülme oranı \%3.20, erkeklerde görülme oranı \%4.10 olarak tespit edildi. Çalıșmamızda sol vertebral arterin arkus aortadan köken aldığı varyasyonun eșlik ettiği diğer varyasyonlar bovine arkı ve ARSA varyasyonu idi.

Sağ subklavyan arterin arkus aortadan son dal olarak köken alması ile karakterize olan aberran sağ subklavian anomalisi (ARSA) çalıșmamızda 37 hastada (\%1.61) görülmekte idi. Bu varyasyonun görülme oranı kadın hastalarda (\%1.56) daha fazla idi. Vücudun sol yarısından bașlayan ve sağ yarısına geçen aberran RS, seyri esnasında \%85 oranında özefagusun arkasından geçmektedir. Daha az sıklıkta ise trakea ve özefagus arasından veya trakeanın önünden de geçebilmektedir.

Çalışmamızda 16 hastada sağ aortik ark varyasyonu izlenmiștir. Hastaların 7'si kadın, 9'u erkek olup görülme oranı cinsiyet farklılığı açısından istatiksel olarak anlamlı idi.

Aort koarktasyonu, genellikle bir jukstaduktal konumda, fokal daralmış aorta segmenti olarak tanımlanır. Aort koarktasyonu genel popülasyonun yaklașık \% 0,06 ile \% 0,08'inde bulunmuştur. Erkeklerde kadınlara göre daha sık görülür (13). Çalıșmamızda 1 hastada aort koarktasyonu izlenmiș olup erkek hasta idi.

Çalıșmamızda nadir görülen çift aortik ark, kommeral divertikül, servikal aortik ark gibi diğer varyasyonlar izlenmemiștir. Çift aortik ark, karotis kommunis ve subklavyen arterin her iki taraftaki ipsilateral arklarından kaynaklanır. Bu düzenleme trakea ve özefagusu tamamen sarar ve tam vasküler halkanın en yaygın nedenidir (14). Kommerell divertikülü, aberran sağ subklavyen arterin aorta orjin düzeyine yakın kesiminde sakküler genișlemesidir. Bu varyasyon bazen anevrizma rüptürü ile sonuçlandığından klinik önemi bulunur (15). Servikal aortik ark, aort arkının ya klavikula seviyesinde ya da hemen üstünde izlenmesi olup arkın normal konuma göre yukarıda olmasıdır (16).

İzole arkus aorta varyasyonları genellikle asemptomatiktir ve radyolojik incelemeler sırasında rastlantısal olarak tespit edilir. Bovine arkının nadiren de olsa öksürük ve dispne gibi bazı klinik semptomlara yol açabileceği bildirilmektedir (17). Arkus aortada bu tip bir varyasyonun varlığı açılar nedeniyle kateterizasyonu ve supraaortik veya serebral damarlara yönelik damar içi girișimleri de zorlaștırmaktadır. Komiyama ve ark. (18) sol vertebral arterin arkus aortadan köken aldığı vakalarda daha yüksek oranda vertebral arter diseksiyonu görüldüğünü bildirmişlerdir. Ayrıca vertebral arterin arkus aortadan çıkmasının hemodinamik değişikliklere yol açarak kafa içi anevrizma olușumuna yol açabileceği düșünülmektedir. ARSA varyasyonu genellikle semptomsuz olmakla birlikte nadiren disfaji lusoria denilen özefagus basısına bağlı yutma güçlüğü ve ağrıya veya trakea basısına bağlı dispne gibi semptomlara yol açabilmektedir $(7,8)$ Ayrıca trakeostomi esnasında bu anatomik varyasyon fark edilmezse ciddi komplikasyonlara yol açılabilir (19). Sağ yerleșimli arkus aorta özofagus ve trakeaya eksternal bası etkisinden dolayı yutma güçlüğü, öksürük, stridor ve nefes darlığı gibi semptomlara neden olabilir $(20,21)$.

Çok kesitli bilgisayarlı tomografi non invaziv bir görüntüleme yöntemi olup multiplanar rekonstruksiyon sağlayarak vasküler anatomiyi çok iyi bir șekilde göstererek varyasyonların tespitinde önemli bir rol oynar. Bununla birlikte ÇKBT tetkiki bütün anatomik yapıları değerlendirmeyi sağlayarak özofagus ve hava yollarına vasküler basıyı göstermesi önemli bir avantajdır (12). Invaziv anjiografi varyasyonları bașarılı bir şekilde göstermekle beraber trake ve özofagus basısını göstermede yeterli değildir. Radyolojik görüntüleme varyasyonların tespitinin yanı sıra ameliyat öncesi kesin cerrahi kararlarda çok yardımcı olur. Torakal aorta anatomisinin ayrıntılı değerlendirilmesi, torasik cerrahi ve endovasküler müdahalenin planlanması için önemlidir. Çünkü torakal aorta varyantların ve anomalilerinin varlığı ve paterni onarım ile ilgili kararlara ek olarak cerrahi insizyonu, kardiyopulmoner bypass kanülasyonunu ve girișimsel yaklașımı etkileyebilir. Torakal aorta anomalileri karotis stent prosedürleri dahil endovasküler tedavinin teknik zorluğunu ve nörolojik komplikasyon riskini artırabilir. Aort anatomisi bilgisi ve torakal aorta anomalilerinin tanımlanması, doğru cerrahi ve müdahale planlamasına izin verir ve olası komplikasyonların önlenmesine yardımcı olur $(6,12,22)$.

Çalışmamızdaki kısıtılıklarımız torasik aorta varyasyonu olan hasta sayımızın ve özellikle çeșitliliğinin az olmasıdır. 


\section{SONUC}

Sonuç olarak, günümüzde torakal aorta varyasyonları yaygın görülmektedir. Çoğunun klinik önemi olmamakla beraber bazıları klinik bulgulara yol açmaktadır. Bununla birlikte torakal aorta varyasyonlarının ve tipinin bilinmesi günümüzde oldukça yaygınlașan tanı ve tedavi amaçlı damar içi ișlemler ve özellikle baș-boyun ve gögüs bölgesinde gerçekleștirilmesi planlanan cerrahi girişimler açısından çok önemlidir. ÇKBT vasküler anatomiyi tam olarak göstererek cerrahiye ve girişimsel ișlemlere yol göstermektedir. Rutin incelemelerde radyolog mevcut bütün varyasyonları raporunda belirtmesi gerekmektedir.

\section{BILDIRIMLER}

Değerlendirme

İç ve dış danışmanlık

Çıkar Çatıșması

Yazarlar bu makale ile ilgili herhangi bir çıkar çatışması bildirmemișlerdir.

Finansal Destek

Yazarlar bu makale ile ilgili herhangi bir malî destek kullanımı bildirmemișlerdir.

\section{Etik Beyan}

Bu çalıșma, birinci yazarın "Çok kesitli bilgisayarlı tomografi ile torasik aortik varyasyonların değerlendirilmesi” bașlıkIı, 2020 tarihli tıpta uzmanlık tezinin yeniden düzenlenmesi ile olușturulmuş olup Mustafa Kemal Üniversitesi Girișimsel Olmayan Klinik Araştırmalar Etik Kurulundan 23.05.2019 tarih ve 06 karar numaralı yazı ile izin alınmıștır. Çalıșmanın hazırlanması sırasında Helsinki Bildirgesi kriterleri göz önünde bulundurulmuștur.

\section{KAYNAKLAR}

1. Adachi B. Das arterien system der Japaner. Vol. 1. Kenkyusha, Kyoto; 1928. pp. 29-41.

2. Ergun E, Șimșek B, Koșar PN, Yılmaz BK, Turgut AT. Anatomical variations in branching pattern of arcus aorta: 64-slice CTA appearance. Surg Radiol Anat 2013;35:503-9. https://doi. org/10.1007/s00276-012-1063-3

3. Kau T, Sinzig M, Gasser J, Lesnik G, Rabitsch E, Celedin S, et al. Aortic development and anomalies. Semin Intervent Radiol; 2007;24:141-52. https://doi.org/10.1055/s-2007-980040.

4. Edwards JE. Anomalies of the derivatives of the aortic arch system. Med Clin of North Am. 1948;32(4):925-49. https://doi. org/10.1016/s0025-7125(16)35662-0.

5. Rosen RD, Bordoni B. Embryology, Aortic Arch. In: StatPearls [Internet]. Treasure Island (FL): StatPearls Publishing; 2020 Jan. 2020 Mar 30.
6. Jakanani GC, Adair W. Frequency of variations in aortic arch anatomy depicted on multidetector CT. Clin Radiol. 2010;65(6):481-7. https://doi.org/10.1016/j.crad.2010.02.003.

7. Natsis KI, Tsitouridis IA, Didagelos MV, Fillipidis AA, Vlasis KG, Tsikaras PD. Anatomical variations in the branches of the human aortic arch in 633 angiographies: clinical significance and literature review. Surg Radiol Anat 2009;31:319-23. https://doi.org/10.1007/s00276-008-0442-2

8. Backer CL, Ilbawi MN, Idriss FS, DeLeon SY. Vascular anomalies causing tracheoesophageal compression. Review of experience in children. J Thorac Cardiovasc Surg 1989;97:725-31. https:// doi.org/10.1016/S0022-5223(19)34517-9

9. Williams GD, Edmonds HW. Variations in the arrangement of the branches arising from the aortic arch in American whites and negroes (A second study). The Anat Rec 2005;62:139-46. https://doi.org/10.1002/ar.1090620203

10. Karacan A, Türkvatan A, Karacan K. Anatomical variations of aortic arch branching: evaluation with computed tomographic angiography. Cardiol Young 2014;24:485-93. https://doi. org/10.1017/S1047951113000656.

11. Ergun O, Tatar IG, Birgi E, Durmaz HA, Akçalar S, Kurt A, et al. Arkus aorta anatomisinin ve dallanma paternindeki varyasyonların anjiyografik olarak değerlendirilmesi. Turk Kardiyol Dern Ars. 2015;43(3):219-26. https://doi.org/10.5543/ tkda.2015.49879.

12. Celikyay ZR, Koner AE, Celikyay F, Denız C, Acu B, Firat MM. Frequency and imaging findings of variations in human aortic arch anatomy based on multidetector computed tomography data. Clin Imaging 2013;37:1011-9. https://doi.org/10.1016/j clinimag.2013.07.008.

13. Agarwala BN, Bacha E, Cao Q, Hijazi ZM, Fulton D, Connolly H, et al. Clinical manifestations and diagnosis of coarctation of the aorta. In: UpToDate. 21 December 2011. Accessed 9 May2014. www. uptodate. com/contentssearch?search $=\& x=14 \& y=8$.

14. Thankavel PP, Brown PS, Lemler MS. Left-dominant double aortic arch in critical pulmonary stenosis and ventricular septal defect. Pediatr Cardiol. 2012;33(8):1469-71. https://doi. org/10.1007/s00246-012-0437-y

15. Faistauer Â, Torres FS, Faccin CS. Right aortic arch with aberrant left innominate artery arising from Kommerell's diverticulum. Radiol Bras. 2016;49(4):264-6. https://doi.org/10.1590/01003984.2013.1934.

16. Dasari TW, Paliotta M. Cervical aortic arch. N Engl J Med. 2014;371(26):e38. https://doi.org/10.1056/NEJMicm1400771

17. Karkoulias KP, Efremidis GK, Tsiamita MS, Trakada GP, Prodromakis EN, Nousi ED, et al. Abnormal origin of the left common carotid artery by innominate artery: a case of enlargement mediastinum. Monaldi Arch Chest Dis 2003;59:222-3.

18. Komiyama M, Morikawa T, Nakajima H, Nishikawa M, Yasui 
T. High incidence of arterial dissection associated with left vertebral artery of aortic origin. Neurol Med Chir (Tokyo) 2001;41:8-11. https://doi.org/10.2176/nmc.41.8

19. Chadha NK, Chiti-Batelli S. Tracheostomy reveals a rare aberrant right subclavian artery; a case report. BMC Ear Nose Throat Disord 2004;4:1. https://doi.org/10.1186/1472-6815-41

20. Özkaya S, Șengül B, Hamsici S, Fındık S. An unusual cause of dyspnea. J Asthma 2010;47:946-8. https://doi.org/10.3109/02 770903.2010.504877
21. Raymond GS, Miller RM, Müller NL, Logan PM. Congenital thoracic lesions that mimic neoplastic disease on chest radiographs of adults. Am J Roentgenol 1997;168:763-9. https://doi.org/10.2214/ajr.168.3.9057531

22. Aboulhoda BE, Ahmed RK, Awad AS. Clinically-relevant morphometric parameters and anatomical variations of the aortic arch branching pattern. Surg Radiol Anat. 2019;41(7):731-44. https://doi.org/10.1007/s00276-01902215-w 